\section{Sex difference in hospitalized patients with COVID-19 infection}

\author{
Heba Wagih Abdelwahab, ${ }^{1}$ \\ Shaker Wagih Shaltout, ${ }^{2}$ \\ Ahmed Mohamed Fouda, ${ }^{1}$ \\ Raed EImetwally Ali, ${ }^{1}$ Nesrein M. \\ Shalaby, ${ }^{1}$ Fatma Elhoseiny, ${ }^{1}$ \\ Nesrine Saad Farrag, ${ }^{3}$ Ahmed Ehab, ${ }^{1,4}$ \\ ${ }^{1}$ Chest Medicine Department, Mansoura \\ University, Mansoura; ${ }^{2}$ Tropical \\ Medicine Department, Port Said \\ University, Port Said; ${ }^{3}$ Community \\ Medicine Department, Mansoura \\ University, Mansoura, Egypt; \\ ${ }^{4}$ Loewenstein Lung Center, Loewenstein, \\ Germany
}

\footnotetext{
Abstract

The pandemic of COVID-19 infection is rapidly progressing to one of the most severe threats to human health. The different responses of the immune system in females and males to a range of infectious and inflammatory stimuli were investigated. We aimed to explore the association of sex with the course of infection among the hospitalized COVID-19 patients. This Comparative cross-sectional study was conducted on RT- PCR positive COVID-19 patients. Severe and critical patients who required hospital or ICU admission were included in the study. The total number of patients was 150 ( 75 males and 75 females) with mean age of $57 \mathrm{Y} \pm 14.7$. There was a statistical significance in age between both groups [mean $\pm \mathrm{SD}$ : males 60.5 (12.2), females 54 (15.3) ( $\mathrm{p}=0: 0.007)]$. The prevalence of diabetes mellitus, hypertension, chronic kidney disease and ischemic heart disease was higher among males but without statistical significance. Consolidation was significantly more prevalent in female group (85.3\% vs $61.3 \%$ in male group). The need of mechanical ventilation was higher in men, but with no statistical significance (44\% Vs 32\%, p=0.302). Also, mortality rate was higher $(48 \%)$ in males than in females $(37.3 \%)$, but with no statistical significance $(p=0.262)$. During the COVID-19 infection, the risk factors of severe disease and progression to the need of mechanical ventilation support in addition to mortality rate are more prevalent among males. However, radiological patterns apart from consolidation, distribution of radiological abnormalities and CT severity score in both groups did not show significant sex difference.
}

\section{Introduction}

The pandemic of the novel coronavirus (COVID-19) evolved after identifying a cluster of pneumonia cases in Wuhan, a city in China, in December 2019. Since then, it becomes an extraordinary international health crisis in over 188 countries in the world. ${ }^{1}$ The COVID-19 infection has various clinical manifestations. The clinical spectrum ranged from mild, uncomplicated illness (about $81 \%$ of the patients), severe illness that required oxygen supplementation (about $14 \%$ of the patients), and acute infection that required ICU admission (about $5 \%$ of the patients. ${ }^{2,3}$ The critical COVID-19 infection is still fulfilling the Berlin criteria to define the ARDS. ${ }^{4}$

The influence of sex in the different responses of the immune system to variable infectious and inflammatory diseases such as TB, malaria, hepatitis, HIV, flu, measles, adenovirus, etc. was investigated. ${ }^{5}$ It was found that women are less susceptible to viral infections in comparison to men. ${ }^{5}$

This may be explained by steroid hormone production by the gonads, factors related to sex chromosomes, and the different innate and adaptive immunity. Sex hormones modulate the innate immune responses to various infectious diseases including viral infections. ${ }^{5}$ The $\mathrm{X}$ chromosome acts on various elements of the immune system such as FOXP3, TLR7, TLR8, CD40L, and CXCR3, which can be over-expressed in women and influence the response to viral infections and vaccinations. ${ }^{6}$ Pandemics and outbreaks have differential impacts on women and men. Global and national strategic plans for COVID-19 preparedness and response must be grounded in solid gender analysis and must ensure meaningful participation of affected groups. ${ }^{5}$

This study aimed to characterize the cohort of the hospitalized COVID-19 patients based on their gender.

\section{Materials and Methods}

This Comparative cross-sectional study was conducted on RT- PCR positive COVID-19 patients. This study was conducted within the required ethics guidelines of the Mansoura institutional research board ethics committee (code number: R.20.06.860).

The study aimed to determine the sex differences in the clinical profile, course, and prognosis of the disease among the hospitalized COVID-19 patients.
Correspondence: Ahmed Ehab, Chest Medicine Department, Mansoura University, Elgmohoria Street, 35516, Mansoura, Egypt; Loewenstein Lung Center, Loewenstein, Germany. Tel.: +201009636591

E-mail: dr.a.ehab@gmail.com.com

Key words: Sex; coronavirus disease; COVID-19 pneumonia; SARS-CoV-2; mortality; gender.

Contributions: HWA, AE: Literature search, data collection, analysis of data, manuscript preparation, study design and review of manuscript; SWS, AMF, RAE, NMS, NSF: Analysis of data, manuscript preparation, and review of manuscript; FE: Data collection, manuscript preparation, and review of manuscript.

Conflict of interest: The authors declare no conflict of interest.

Availability of data and materials: All data generated or analyzed during this study are included in this published article.

Ethics approval and consent to participate: This study was conducted within the required ethics guidelines of Mansoura institutional research board ethics committee (code number: R.20.06.860), Egypt

Informed consent: Written informed consent was obtained from a legally authorized representative(s) for anonymized patient information to be published in this article.

Received for publication: 5 May 2021

Revision received: 18 September 2021

Accepted for publication: 29 September 2021

This work is licensed under a Creative Commons Attribution NonCommercial 4.0 License (CC BY-NC 4.0).

(C) Copyright: the Author(s), 2021

Licensee PAGEPress, Italy

Chest Disease Reports 2021; 8:9842

doi:10.4081/cdr.2021.9842

\section{Patients}

Severe and critical - according to the WHO definition ${ }^{3}$ - confirmed patients with RT- PCR positive COVID-19 necessitating hospital admission were included in the study.

The severe COVID-19 infection is defined by the presence of oxygen saturation $<90 \%$ on room air or respiratory rate $>$ 30 breaths per minute in adults or signs of severe respiratory distress, i.e., accessory muscle use, inability to complete whole sentences. While acute COVID-19 infection is defined by the presence of the ARDS, sepsis, septic shock, the need for vasopres- 
sor therapy, or the need for non-invasive or invasive mechanical ventilation. ${ }^{3}$

Patients below 18 years old were excluded. The sample size was calculated for the comparative cross-sectional study by using EPI INFO version 7.2.2.16.

The following data was collected: i) Medical history: age, sex, occupation, comorbidities, previous treatment; ii) Radiological data from chest CT: a) Radiological pattern: Radiological terms (ground-glass opacity (GGO), crazy paving pattern, pulmonary consolidation) were defined according to the standard glossary for thoracic imaging reported by the Fleischner Society. ${ }^{7}$ Other features such as fibrosis, subpleural lines, "halo sign," were also described; b) Distribution of lung abnormalities: predominately peripheral, central, or both peripheral and central; c) A semi-quantitative CT severity scoring proposed by Pan et al. ${ }^{8}$ was calculated per each of the five lobes considering the extent of anatomic involvement, as follows: 0: no involvement; $1:<5 \%$ involvement; $2: 5-$ $25 \%$ involvement; $3: 26-50 \%$ involvement; 4: 51-75\% involvement; $5:>75 \%$ involvement. The summation of each lobar score resulted in a global CT score (0 to 25$)$; iii) Laboratory data: D-dimer, CRP, CBC; iv) Outcome assessment, including need of oxygen, need of mechanical ventilatio, improvement in clinical data, and mortality.

\section{Statistical analysis of the data}

The collected data was prepared, tabulated, and statistically analyzed using the Statistical Package for Social Science (SPSS) version 26. Frequencies and proportions were used to present categorical variables. In contrast, means (SD) or Median (min-max) were used to present continuous data according to the Shapiro-Wilk testing of normality of variables. Significance testing was being done using the Chi-Square test, or Fisher's exact test for categorical variables. Independent t-test and MannWhitney U test were used for testing significance among continuous variables, wherever appropriate. The level of significance will be set at $\mathrm{p}<0.05 \%$.

\section{Results}

In our study, 150 confirmed COVID-19 patients (severe and critical patients) were included. Regarding sex, the study included 75 males and 75 females, with a mean age of $57 \mathrm{Y} \pm 14.7$. Nearly one-third of participants had Diabetes mellitus, 37.3\% had hypertension, $12.7 \%$ had ischemic heart disease, $6.7 \%$ had chronic kidney disease, $5.3 \%$ had chronic liver disease. About $62 \%$ of studied patients were classified as severe COVID (Table 1 and Figure 1).

The results of this study showed that there was a statistically significant difference in age between both groups [mean \pm SD: males 60.5 (12.2), females 54 (15.3) $(\mathrm{p}=0: 0.007)]$. Also, a history of previous ischemic cerebral stroke was more prevalent among males $(10.7 \%)$ than females
$(1.3 \%) \quad$ with statistical significance $(p=0.034)$. The prevalence of diabetes mellitus, hypertension, chronic kidney disease, and ischemic heart disease was higher among males than females but without statistical significance. In addition, bronchial asthma was more prevalent among females than males, without statistically significant difference (Table 2).

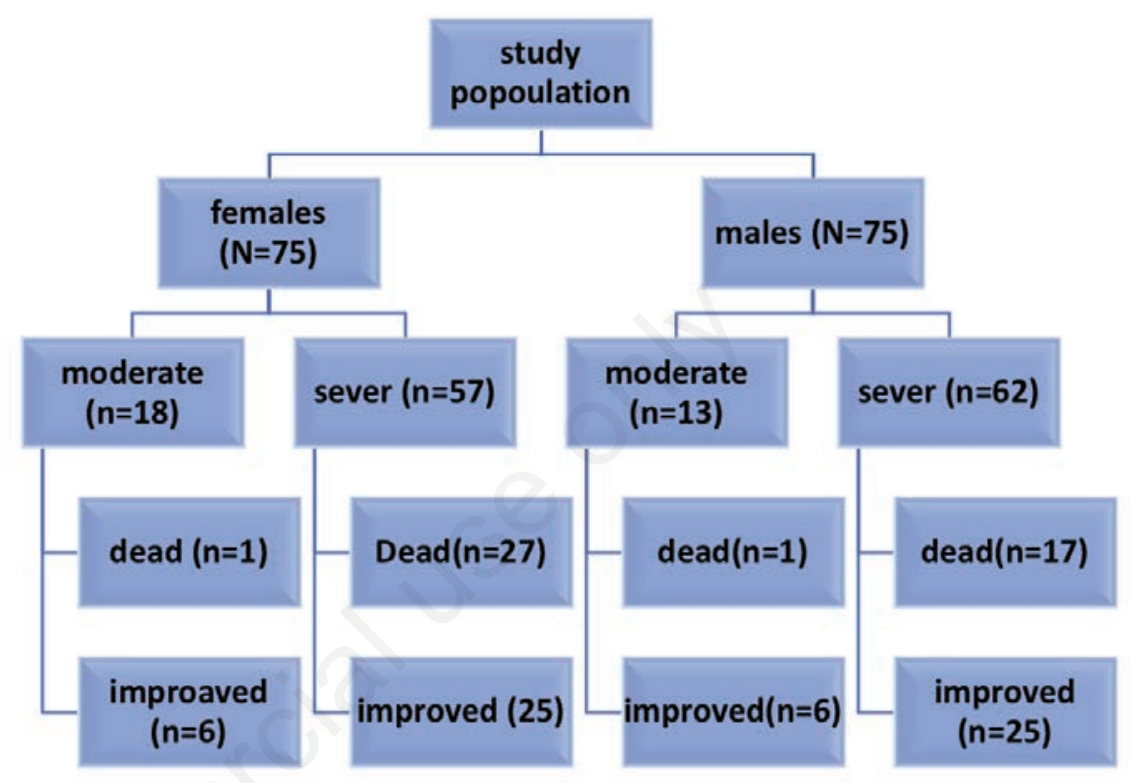

Figure 1. Flowchart of the studied population.

Table 1. Characteristics of the patients studied $(\mathrm{N}=150)$.

\begin{tabular}{lcc}
\hline Parameter & N & $\%$ \\
Age mean (SD) & $57(14.7)$ & \\
Sex & & 50 \\
$\quad$ Male & 75 & 50 \\
$\quad$ Female & 75 & \\
Comorbidity & & 32.7 \\
$\quad$ Diabetes mellitus & 49 & 37.3 \\
$\quad$ Hypertension & 56 & 3.3 \\
Cardiac & 5 & 12.7 \\
Ischemic heart disease & 19 & 6.7 \\
Chronic kidney disease & 10 & 5.3 \\
Chronic liver disease & 8 & 4 \\
Autoimmune disease & 6 & 2 \\
Bronchial asthma & 3 & 6 \\
Cerebral Stroke & 9 & 2 \\
Malignancy & 3 & 62 \\
COVID-19 clinical classification & & 38 \\
$\quad$ Severe & 93 & \\
Critical & 57 & 77.3 \\
\hline GIT symptoms & & 22.7 \\
$\quad$ No & 116 & 42.6 \\
Yes & 34 & 57.4 \\
Outcome & & \\
Improved & 64 & \\
Dead & 86 & \\
\hline & & \\
\hline
\end{tabular}


As regards radiological data, consolidation was significantly more prevalent in the female group $(85.3 \%$ vs $61.3 \%$ in the male group, $\mathrm{p}=0.035$ ). However, Other radiological patterns, distribution of radiological abnormalities, and CT severity score in both groups did not show statistically significant differences (Table 3).

The proportion of studied males who needed mechanical ventilation was higher than that in females, but with no statistical significance (44\% vs 32\%, $\mathrm{p}=0.302)$. Also, the mortality rate was higher $(48 \%)$ in males than in females $(37.3 \%)$ but with no statistical significance $(\mathrm{p}=0.262)$. In addition, the presence of gastrointestinal symptoms also was not different between both groups (Table 4).

\section{Discussion}

Until now, many aspects of the COVID19 infection are still not apparent, and a clear picture of the epidemiology of this COVID-19 is not yet well understood. The knowledge about the immune response to the COVID-19 infection is still evolving. ${ }^{9}$ Our study aimed to determine the sex characteristics among the hospitalized patients with severe and critical illness SARS-COV2 infection who were admitted to Mansoura university quarantine, Egypt.

The difference of immune response to infectious agents according to gender was observed with higher susceptibility to infection and development of the resistance in male patients. Mostly it is related to androgens which affect the host immunity and disease-resistant genes. ${ }^{10}$

The mean age of all included patient was 57 years old. The older age was investigated in many studies as a risk factor for worse outcomes of COVID-19 infection. However, we observed a statistical difference in the age between studied males and females with the tendency of older age in males (60.5 years old). Older age was observed as a risk factor for COVID-19 infection without difference between ICU and non-ICU patients. ${ }^{11}$ The results of this study showed a statistically significant difference in age between both groups (mean age in males was 60 and was 54 in females). These results are compatible with Goujon et al. ${ }^{12}$ which illustrated that more cases were notified among men aged from 55 to 80 years old than women. In comparison, higher numbers of mild cases are reported among women aged from 15 to 55 years.

Hypertension (37.3\%) then DM $(32.7 \%)$ were the most common observed comorbidities in the study. Pre-excising cardiovascular conditions, especially hypertension, are now recognized as one of the demographic risk factors that are associated with a worse outcome in COVID-19 infection. ${ }^{13,14}$ Similarly, type II DM was observed in $30.1 \%$ in the infected patients. They were reported by Instituto Superiore di Sanita (Italy). ${ }^{15}$ This could be explained by endothelial dysfunction as common findings in cardiovascular and DM patients, especially within elderly patients. ${ }^{16,17}$ Additionally, it suggested that cardiovascular patients were more vulnerable to COVID-19 infection due to higher ACE2 expression in vascular and heart tissues. ${ }^{18}$ Tissues rich with ACE2 are the primary binding site for virus entry in the cells. ${ }^{19}$ Moreover, cardiac injury is reported in COVID-19 infection and independently related to increased mortality in COVID-19 patients. ${ }^{20}$ This may be caused by endothelial damage by the massive inflammatory changes complicating severe COVID-19 infection. ${ }^{20}$

Consolidation was prevalent in the stud-

ied female $(85.3 \%$ vs $61.3 \%$ in males, $\mathrm{p}=0.035)$. However, other radiological patterns and distribution of radiological abnormalities in males and females did not show significant differences. Similarly, Moradi et $a{ }^{21}$ found no significant differences in chest CT involvement patterns between men and women.

Also, CT severity scores in both studied groups did not show significant differences in our study. In contrast to Dangis et al., ${ }^{22}$ who found a more excellent CT severity score in men (9.25 versus 7.04.8, p:0.001) with a trend toward more bilateral lung involvement $\quad(89.3 \%$ versus $78.8 \%$,

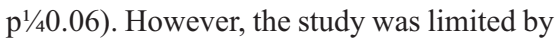
a lack of information on whether this more extensive lung involvement on chest CT correlated with a more adverse clinical outcome in men during follow-up. ${ }^{22}$ Nevertheless, women younger than 60 years had a higher CT score that indicated an unfavorable prognosis like ICU admission

Table 2. Gender difference in age and comorbidities among studied patients.

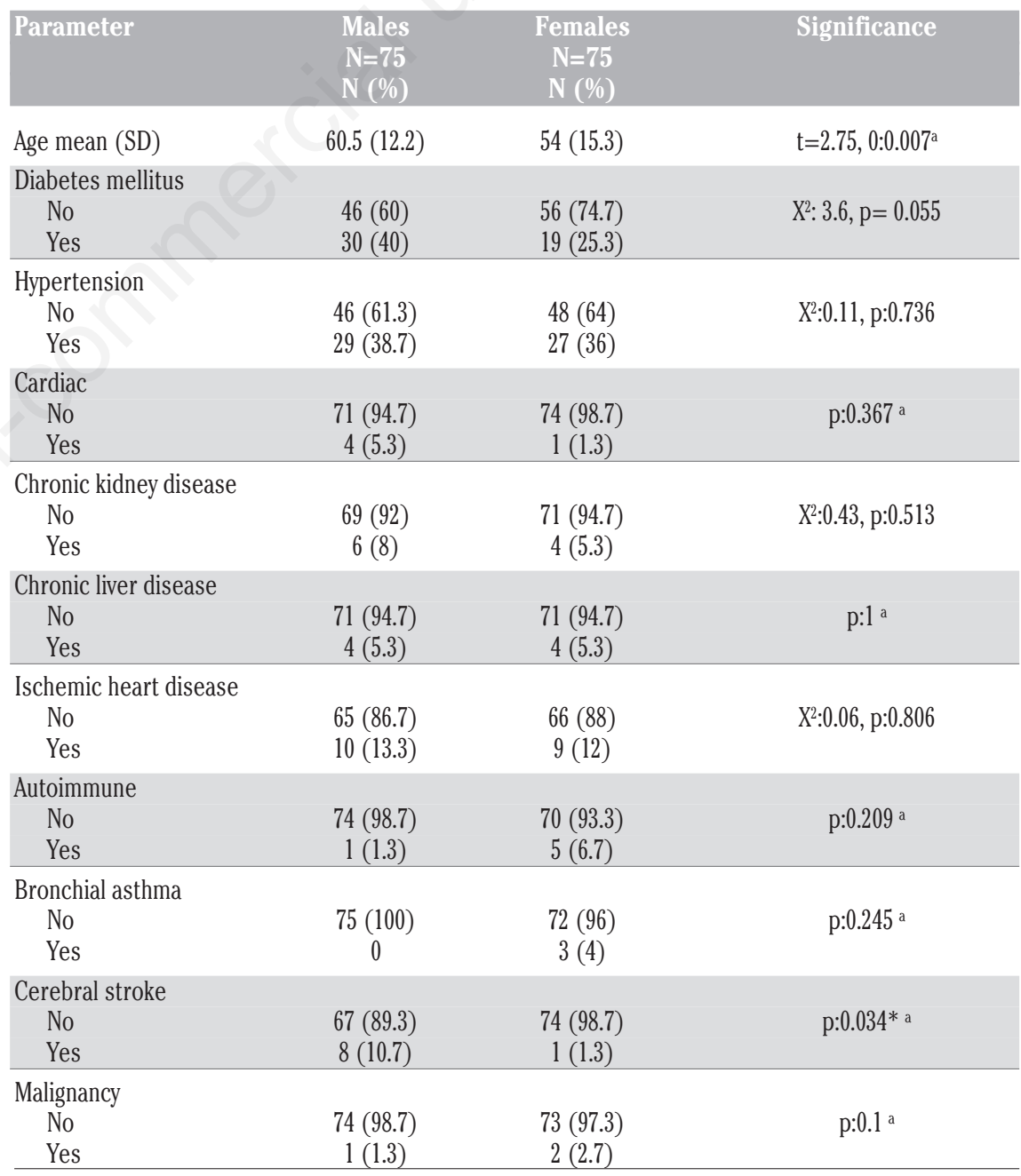

andependent t-test, b: Fisher's exact test 
or death. ${ }^{21}$

The need for mechanical ventilation support and mortality rate in this study was higher in males than in females, but with no statistical significance. The higher incidence of comorbidities may explain those findings, e.g., IHD, hypertension, and especially DM in male patients compared to the studied females as explained above.

Our findings could be explained on behave the known effect of the sex hormone on the innate and adaptive immune response..$^{23}$ The higher morbidity and mortality among the male patients may be explained by the stimulatory effect of testosterone hormone of both AngiotensinConverting Enzyme (ACE 2) and
Transmembrane Protease Serine-Type 2 (TMPRSS2), leading to increase viral load and delay the virus clearance. On the other hand, in female patients, the interaction of the renin-angiotensin-aldosterone system as well as the immune stimulatory genes which present on X Chromosome..$^{23,24}$

A study conducted by Cagnacci and Xholli ${ }^{25}$ and data from the World Health Organization (WHO) and China ${ }^{26}$ showed significantly higher mortality rates in male patients with COVID-19. Also, critically ill men patients who needed admission to the ICU were twice that of women. ${ }^{27}$ Additionally, the age-independent disease severity and mortality were higher in men. ${ }^{28}$ Many factors (e.g., social, genetic, and

Table 3. Sex-specific analysis of differences in the radiological parameters of studied patients.

\begin{tabular}{|c|c|c|c|}
\hline Parameter & $\begin{array}{l}\text { Males } \\
\mathrm{N}=75 \\
\mathrm{~N}(\%)\end{array}$ & $\begin{array}{l}\text { Females } \\
N=75 \\
N(\%)\end{array}$ & Significance \\
\hline Severity score median (min-max) & $13(5-25)$ & $12(7-22)$ & Z: 0.04, P: 0.962 \\
\hline $\begin{array}{l}\text { Crazy paving } \\
\text { No } \\
\text { Yes }\end{array}$ & $\begin{array}{l}44(58.7) \\
31(41.3)\end{array}$ & $\begin{array}{l}39(52) \\
36(48)\end{array}$ & $\mathrm{X}^{2}: 0.37, \mathrm{p}: 0.543$ \\
\hline $\begin{array}{l}\text { Consolidation } \\
\text { No } \\
\text { Yes }\end{array}$ & $\begin{array}{l}29(38.7) \\
46(61.3)\end{array}$ & $\begin{array}{l}11(14.7) \\
64(85.3)\end{array}$ & $\mathrm{X}^{2}: 4.4, \mathrm{p}: 0.035^{*}$ \\
\hline $\begin{array}{l}\text { Vascular dilatation } \\
\text { No } \\
\text { Yes }\end{array}$ & $\begin{array}{l}12(16) \\
63(84)\end{array}$ & $\begin{array}{l}14(18.7) \\
61(81.3)\end{array}$ & P:1 \\
\hline $\begin{array}{l}\text { Subpleural band } \\
\text { No } \\
\text { Yes }\end{array}$ & $\begin{array}{l}60(80) \\
15(20)\end{array}$ & $\begin{array}{l}62(82.6) \\
13(17.3)\end{array}$ & $\mathrm{X}^{2}: 0.01, \mathrm{p}: 1$ \\
\hline $\begin{array}{l}\text { Distribution of lung abnormalities } \\
\text { Peripheral } \\
\text { Peripheral and central }\end{array}$ & $\begin{array}{l}39(52) \\
36(48)\end{array}$ & $\begin{array}{l}31(41.3) \\
44(58.7)\end{array}$ & $\mathrm{X}^{2}: 0.45, \mathrm{p}: 0.501$ \\
\hline $\begin{array}{l}\text { Halo sign } \\
\text { No } \\
\text { Yes }\end{array}$ & $\begin{array}{l}49(65.3) \\
26(34.7)\end{array}$ & $\begin{array}{l}47(62.7) \\
28(37.3)\end{array}$ & $\mathrm{X}^{2}: 0.05, \mathrm{p}: 0.832$ \\
\hline $\begin{array}{l}\text { GGO } \\
\text { No } \\
\text { Yes }\end{array}$ & $\begin{array}{l}17(22.7) \\
58(77.3)\end{array}$ & $\begin{array}{l}16(21.3) \\
59(78.7)\end{array}$ & $\mathrm{X}^{2}: 0.001, \mathrm{p}: 0.974$ \\
\hline
\end{tabular}

Table 4. Sex-specific analysis of differences in the clinical parameters of studied patients.

\begin{tabular}{|c|c|c|c|}
\hline Parameter & $\begin{array}{l}\text { Males } \\
\mathrm{N}=75 \\
\mathrm{~N}(\%)\end{array}$ & $\begin{array}{l}\text { Females } \\
\begin{array}{l}\mathrm{N}=75 \\
\mathrm{~N}(\%)\end{array}\end{array}$ & Significance \\
\hline $\begin{array}{l}\text { GIT symptoms } \\
\text { No } \\
\text { Yes }\end{array}$ & $\begin{array}{l}60(80) \\
15(20)\end{array}$ & $\begin{array}{l}56(74.7) \\
19(25.3)\end{array}$ & $X^{2}: 0.4, p: 0.526$ \\
\hline $\begin{array}{l}\text { Respiratory support } \\
\text { O2 (severe) } \\
\text { Mechanical ventilation (critical) }\end{array}$ & $\begin{array}{l}42(56) \\
33(44)\end{array}$ & $\begin{array}{l}51(68) \\
24(32)\end{array}$ & $\mathrm{X}^{2}: 2.3, \mathrm{p}: 0.302$ \\
\hline $\begin{array}{l}\text { Outcome } \\
\text { Dead } \\
\text { Improved }\end{array}$ & $\begin{array}{l}36(48) \\
39(52)\end{array}$ & $\begin{array}{l}28(37.3) \\
47(62.7)\end{array}$ & $\mathrm{X}^{2}: 1.2, \mathrm{p}: 0.262$ \\
\hline
\end{tabular}

immunological) may contribute to males' overall higher morbidity and mortality rate. There is a high rate of smoking among males compared to females in Egypt, ${ }^{29}$ and therefore, smoking is associated with higher ACE2 receptors expression, which enhanced the virus entry. ${ }^{30}$ Furthermore, the ACE2 gene is located on the $\mathrm{X}$ chromosome, and higher circulating ACE2 levels are observed in men. ${ }^{28}$ The absence of significant differences between both sexes in our study may refer to our study's nature, which included only moderate and severe cases. Meanwhile, other studies and data reported mortality and severity rates among the cohort of infected patients. This allows for consideration of severity as a predictor of the outcome. It was reported that the severity among males was higher than females.

\section{Reference}

1. Pérez-López FR, Tajada M, SavirónCornudella R, et al. Coronavirus disease 2019 and gender-related mortality in European countries: A meta-analysis. Maturitas 2020;141:59-62.

WHO. Clinical management of severe acute respiratory infection when COVID-19 is suspected. Accessed May 10, 2020. Available from: https://www.who.int/publicationsdetail/clinical-management-of-severeacute-respiratory-infection-whennovel-coronavirus-(ncov)-infection-issuspected

3. WHO. Corticosteroids for COVID-19. Accessed December 4, 2020. Avaiable from: https://www.who.int/publications/i/item/WHO-2019-nCoVCorticosteroids-2020.1.

4. Ranieri VM, Rubenfeld GD, Thompson BT, et al. Acute respiratory distress syndrome: The Berlin definition. JAMA 2012;307:2526-33.

5. Conti P, Younes A. Coronavirus cov19/sars-cov-2 affects women less than men: Clinical response to viral infection. J Biol Regul Homeost Agents 2020;34:339-43.

6. Quakkelaar ED, Melief CJM. Experience with synthetic vaccines for cancer and persistent virus infections in nonhuman primates and patients. Adv Immunol 2012;114:77-106.

7. Hansell DM, Bankier AA, MacMahon $\mathrm{H}$, et al. Fleischner Society: Glossary of terms for thoracic imaging. Radiology 2008;246:697-722.

8. Pan F, Ye T, Sun P, et al. Time course of lung changes at chest $\mathrm{CT}$ during recovery from Coronavirus disease 2019 
(COVID-19). Radiology 2020;295:715721.

9. Wiersinga WJ, Rhodes A, Cheng AC, et al. Pathophysiology, transmission, diagnosis, and treatment of coronavirus disease 2019 (COVID-19): A review. JAMA 2020;324:782-793.

10. Klein SL. The effects of hormones on sex differences in infection: from genes to behavior. Neurosci Biobehav Rev 2000;24:627-38.

11. Huang C, Wang Y, Li X, et al. Clinical features of patients infected with 2019 novel coronavirus in Wuhan, China. Lancet 2020;395:497-506.

12. Goujon A, Natale F, Ghio D, et al. Age, gender, and territory of COVID-19 infections and fatalities. EUR 30237 EN, Publications Office of the European Union, Ispra, 2020.

13. Guzik TJ, Mohiddin SA, Dimarco A, et al. COVID-19 and the cardiovascular system: Implications for risk assessment, diagnosis, and treatment options. Cardiovasc Res 2020;116:1666-87.

14. Shi S, Qin M, Shen B, et al. Association of Cardiac Injury with Mortality in Hospitalized Patients with COVID-19 in Wuhan, China. JAMA Cardiol 2020;5:802-10.

15. Istituto Superire di Sanità. Characteristics of COVID-19 patients dying in Italy. Accessed December 6, 2020. Available from: https://www.epicentro.iss.it/en/coronavirus/sars-cov-2analysis-of-deaths
16. Dorigo P, Fraccarollo D, Santostasi G, Maragno I. Impairment of endotheliumdependent but not of endothelium-independent dilatation in guinea-pig aorta rings incubated in the presence of elevated glucose. $\mathrm{Br} \mathrm{J}$ Pharmacol 1997;121:972-6.

17. Perticone F, Ceravolo R, Pujia A, et al. Prognostic significance of endothelial dysfunction in hypertensive patients. Circulation 2001;104:191-6.

18. He L, Mäe MA, Muhl L, et al. Pericytespecific vascular expression of SARSCoV-2 receptor ACE2 - implications for microvascular inflammation and hypercoagulopathy in COVID-19. BioRxiv, May 2020. doi:10.1101/2020.05.11.088500

19. Yan R, Zhang Y, Li Y, et al. Structural basis for the recognition of SARS-CoV2 by full-length human ACE2. Science 2020;367:1444-48.

20. Froldi G, Dorigo P. Endothelial dysfunction in Coronavirus disease 2019 (COVID-19): Gender and age influences. Med Hypotheses 2020;144:110015.

21. Moradi B, Ghanaati H, Kazemi MA, et al. Implications of sex difference in CT scan findings and outcome of patients with COVID-19 pneumonia. Radiol Cardiothorac Imaging 2020;2:e200248.

22. Dangis A, De Brucker N, Heremans A, Gillis M, Frans J, Demeyere A, Symons R. Impact of gender on extent of lung injury in COVID-19. Clin Radiol
2020;75:554-6.

23. Kloc M, Ghobrial RM, Kubiak JZ. The role of genetic sex and mitochondria in response to COVID-19 infection. Int Arch Allergy Immunol 2020;181:62934.

24. Chanana N, Palmo T, Sharma K, et al. Sex-derived attributes contributing to SARS-CoV-2 mortality. Am J Physiol Endocrinol Metab 2020;319:E562-7.

25. Cagnacci A, Xholli A. Age-related difference in the rate of coronavirus disease 2019 mortality in women versus men. Am J Obstet Gynecol 2020;223:453-4.

26. WHO. COVID-19 situation reports. Accessed May 11, 2020. Available from: https://www.who.int/emergencies/diseases/novel-coronavirus2019/situation-reports

27. Xu B, Gutierrez B, Mekaru S, et al. Epidemiological data from the COVID19 outbreak, real-time case information. Sci Data 2020;7:106.

28. Jin J-M, Bai P, He W, et al. Gender differences in patients with COVID-19: Focus on severity and mortality. Front Public Heal 2020;8:152.

29. WHO. Global Report on Trends in Prevalence of Tobacco Smoking. 2015. Accessed March 15, 2020.https://apps.who.int/iris/handle/10 $665 / 156262$

30. Cai H. Sex difference and smoking predisposition in patients with COVID-19. Lancet Respir Med 2020;8:e20. 